\title{
A biomechanical research of foot pressure for lower extremity in gait wearing trail walking shoes
}

\author{
Seung-Bum Park ${ }^{1 *}$, Sae-Yeon Lee², Seong-Mi Kim², Yu-Jin Hwang², Kyoung-Youl Yoo² \\ From 4th Congress of the International Foot and Ankle Biomechanics (i-FAB) Community \\ Busan, Korea. 8-11 April 2014
}

The aim of this study is to analyze foot pressure distribution of trail walking shoes while walking. Hiking, a recreational activity which is able to exercise whole body in the nature without any cost, has compositive effects which can reduce stress, strengthen muscles of entire body and improve cardiopulmonary function [1]. The Topography is hard near the surface and has rough characteristic because of rocks. These condition can lead to injuries to feet in hiking and aggravating fatigability of foot when people hike for a long time [2],so hiking boots which are specially functioned are encouraged because walking on the rough surface has latent dangerousness of injury [3]. Trail walking shoes generally provide more stability and support than regular walking shoes. Trail walking shoes are for natural trails. In rocky, rooted, dusty and muddy trails, a trail walking shoe gives added traction and support.

Ten healthy males participated in this study. All subjects were free of lower extremity pain, history of serious injuries or operative treatment or subjective symptoms interfering with walking. Each subject wore four different shoe types during walking trials on a treadmill at a constant speed of $4.2 \mathrm{~km} /$ hour. Pressure distribution data (contact area, maximum force, peak pressure, maximum mean pressure) were collected with pressure device at a sampling rate of $100 \mathrm{~Hz}$. Shoes used in the experiment are which developed in four shoes. Developed trail walking shoes (Type A), first developed trail walking shoes (Type B) and other company's trail walking shoes (Type C, Type D) are selected for the experiment. Tested about 'Comparison in Lightweightedness' among the shoes (Figure 1). 'Comparison in Lightweightedness's result is

\footnotetext{
* Correspondence: sbpark@shoenet.org

${ }^{1}$ Footwear Biomechanics Team, Footwear Industrial Promotion Center, Busan, Korea

Full list of author information is available at the end of the article
}

Type A (324.92 g) < Type B (350.70 g) < Type C $(374.67 \mathrm{~g})<$ Type D (397.16 g).

Contact area of functional shoes (Type A) increased in comparison to general shoes (Type C, Type D). At the same time, foot pressure decreased in comparison to general shoes (Type C, Type D). It is expected that Type A Functional shoes give more comfort and fit by increasing the contact area and decreasing peak pressure.

In the result of the analysis of plantar pressure, Type A reported higher than other shoes on the forefoot. At the maximum force, Type $A$ is observed as the smallest maximum force in almost part. These results, which is similar to Park (2009)'s research [3], decreased the confining pressure which can lead the deformation of forefoot's toe. In the maximum pressure result, the outcome is similar to maximum force, which the smallest is Type $\mathrm{A}<$ Type $\mathrm{D}<$ Type $\mathrm{B}<$ Type $\mathrm{C}$. This can decline the impulse which occurs in heel strike section, as a result, this can decrease the fatigability of foot in long-time walking. In addition, similar to Oh and Lee (2009)'s research [4], it can lighten the impulse force delivered to the body, as being the important factor which can decrease the weight to the leg joint. As examining the result of the average pressure, Type $\mathrm{A}<$ Type $\mathrm{C}<$ Type $\mathrm{D}<$ Type $\mathrm{B}$ is observed.

In this thesis, we analyzed the contact area of plantar pressure, maximum force, maximum pressure, average pressure. Through this result, we can know impact force alleviation for foot and physical fatigue, too.

When considering the pressure change of the foot, Type A's contact area of foot is wider than the others. So, its wearing feeling will be better than the others. In case of maximum pressure, it is lower than the others and mid foot, hind foot's result is similar. So, we expect 'shockproof and to disperse pressure' will be good. Also, 

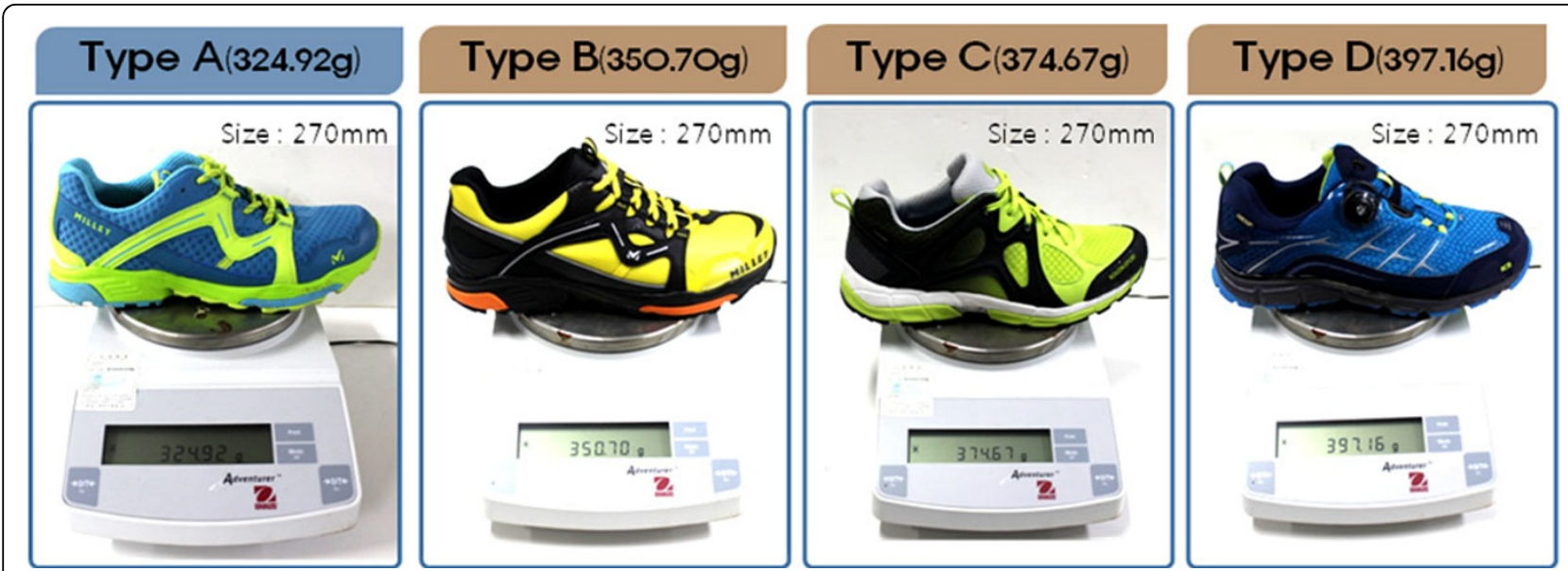

Figure 1 Type A: developed trail walking shoes, Type B: first developed trail walking shoes, Type C, D: other company's trail wxalking shoes

Table 1 Result of Foot Pressure

\begin{tabular}{|c|c|c|c|c|c|c|c|c|c|c|}
\hline \multirow[t]{2}{*}{ Mask } & \multicolumn{5}{|c|}{ Contact Area $\left(\mathrm{cm}^{2}\right)$} & \multicolumn{5}{|c|}{ Maximum Force(N) } \\
\hline & A & CA & B & $\mathrm{C}$ & D & A & CA & B & C & D \\
\hline Total & 142.187 & 142.739 & 142.049 & 146.076 & 139.403 & 677.276 & 703.008 & 708.275 & 715.217 & 690.800 \\
\hline M1 & 58.507 & 58.046 & 57.975 & 57.618 & 58.474 & 558.903 & 552.363 & 568.875 & 539.680 & 565.046 \\
\hline M2 & 42.356 & 44.444 & 42.660 & 47.957 & 40.930 & 152.873 & 194.191 & 168.769 & 215.201 & 173.182 \\
\hline M3 & 40.664 & 39.659 & 40.782 & 39.834 & 39.483 & 402.950 & 412.355 & 436.040 & 407.802 & 416.908 \\
\hline \multirow[t]{2}{*}{ Mask } & \multicolumn{5}{|c|}{ Peak Pressure(kPa) } & \multicolumn{5}{|c|}{ Maximum Mean Pressure(kPa) } \\
\hline & A & CA & B & $C$ & D & A & $C A$ & B & $C$ & D \\
\hline Total & 237.516 & 272.143 & 256.418 & 273.346 & 270.940 & 78.084 & 79.048 & 79.767 & 76.533 & 81.563 \\
\hline $\mathrm{M} 1$ & 235.927 & 268.839 & 256.130 & 272.763 & 264.915 & 95.864 & 95.639 & 98.354 & 94.568 & 96.709 \\
\hline M2 & 87.566 & 111.221 & 98.818 & 126.280 & 96.161 & 44.034 & 50.660 & 47.934 & 53.151 & 48.168 \\
\hline M3 & 166.622 & 177.161 & 171.323 & 162.103 & 192.218 & 99.827 & 104.309 & 107.090 & 102.840 & 105.777 \\
\hline
\end{tabular}

* CA: Control Average $=($ Type $C+$ Type D $) / 2$

with foot and shoe contact area's increase, there may be amaximum force and maximum pressure decrease. So, it can decrease the foot's and pelvic limb's fatigue.

We offer the data of the dispersing pressure functionality of walking hiking shoes, so it can be of help to a product's functionality improvement.

\section{Authors' details}

'Footwear Biomechanics Team, Footwear Industrial Promotion Center, Busan, Korea. ${ }^{2}$ Busanil Science High School, Busan, Korea.

Published: 8 April 2014

\section{References}

1. Lee HS, Jung GS, Yoo HH: Slope Analysis of Mountain Trail Using Mobile GPS. The Korean Society for GeoSpatial Information System 2009, 17(2):81-90.

2. Park SB, Lee JS: Analyses of GRF \& Insole Foot-Pressure Distribution: Gait Patterns and Types of Trekking Boots. Korean Journal of Sport Biomechanics 2007, 17(4):190-200.

3. Hettinga BA, Stefayshyn DJ, Fairbairn JC, Worobets JT: Biomechanical effects of hiking on a non-uniform surface. Proceeding. of the 7th Symposium Footwear Biomechanics, Cleveland, OH, USA; 2005, 41-42.
4. Park JJ: A Comparative Analysis on Changes of Foot Pressure by Shoe Heel Height during Walking. Korean Journal of Sport Biomechanics 2009, 19(4):771-778.

5. Oh YJ, Lee CM: The Study on 3-Axes Acceleration Impact of Lower Limbs Joint during Gait. Journal of the Ergonomics Society of Korea 2009, 28(3):33-39.

doi:10.1186/1757-1146-7-S1-A136

Cite this article as: Park et al:: A biomechanical research of foot

pressure for lower extremity in gait wearing trail walking shoes. Journal

of Foot and Ankle Research 2014 7(Suppl 1):A136. 